\title{
Pengalaman Keluarga Merawat Pasien Halusinasi Pendengaran di Rumah Sakit Jiwa Jambi
}

\author{
Vevi Suryenti Putri ${ }^{1}$, Mustikasari ${ }^{2}$, Renidayati ${ }^{3}$ \\ ${ }^{1}$ Program Studi Megister Keperawatan Peminatan Keperawatan Jiwa Universitas Andalas \\ ${ }^{2}$ Staf Pengajar Fakultas Keperawatan Universitas Indonesia \\ ${ }^{3}$ Staf Pengajar Fakultas Keperawatan Poltekes Kemenkes Padang \\ Correspondence email: vevisuryentiputri.2010@gmail.com
}

\begin{abstract}
Abstrak. Tujuan dalam penelitian ini untuk mengetahui pengalaman keluarga merawat halusinasi pendengaran di Rumah Sakit Jiwa Jambi. Jenis penelitian yang dilakukan adalah penelitian kualitatif dengan studi fenomenologi deskrifitif. Partisipan dalam penelitian ini adalah anggota keluarga inti yang melakukan perawatan pada keluarganya yang menderita halusinasi pendengaran yang telah dipilih sesuai dengan kriteria yang telah ditetapkan yaitu berjumlah 7 partisipan. Metode pengambilan sampel dengan purposive sampling dengan analisa data metode Colaizzi. Uji data dengan menggunakan Credibility dengan membercheck, Transferability, Dependability, Comfirmability. Penelitian mendapatkan hasil empat tema yaitu: 1)Jenis perawatan keluarga di rumah, 2) Temuan keluarga dalam merawat, 3) Jenis penyelesaian masalah daam keluarga 4) Pelayanan yang di dapatkan
\end{abstract}

Kata Kunci: Pengalaman keluarga; halusinasi pendengaran; merawat

\begin{abstract}
The purpose of this study was to determine the experience of families caring for auditory hallucinations in Jambi Mental Hospital. This type of research is a qualitative research with a descriptive phenomenological study. Participants in this study were nuclear family members who cared for their families suffering from auditory hallucinations that had been selected according to predetermined criteria, totaling 7 participants. The sampling method was purposive sampling with Colaizzi method data analysis. Test data using credibility with member check, transferability, dependability, confirmation. The study obtained the results of four themes, namely: 1) Types of family care at home, 2) Findings of families in caring, 3) Types of problem solving in families 4) Services received
\end{abstract}

Keywords: Family experience; auditory hallucinations; caring

\section{PENDAHULUAN}

Kesehatan jiwa merupakan masalah yang sangat serius dan memerlukan perhatian khusus, salah satu masalah kesehatan jiwa yang paling banyak ditemui adalah skizofrenia dengan masalah keperawatan halusinasi pendengaran. Menurut Townsend (2011), halusinasi merupakan keadaan dimana seseorang mengalami perubahan atau kelainan dalam respons pada setiap stimulus. Klien dengan halusinasi sering mengalami kekambuhan. Beberapa faktor penyebab kekambuhan adalah kegagalan regimen terapi klien yang telah diprogramkan seperti proses pengobatan, peran, motivasi dan dukungan keluarga yang tidak adekuat (Kozier, 2010). Keluarga memberikan sumber daya penting dalam memberikan layanan kesehatan yang efektif, pentingnya keluarga dalam perawatan pasien gangguan jiwa, karena akan membantu memulihkan keadaan penderita, mengembangkan dan meningkatkan kemampuan keluarga dalam mengatasi masalah kesehatan keluarga tersebut sehingga status sehat dan sakit dari anggota keluarga saling mempengaruhi, satu penyakit dalam keluarga akan mempengaruhi seluruh keluarga dan interaksinya. Penelitian Vander (2012), meneliti tentang A Qualitative Study of Coping with Voices Hearing of People with Schizofrenia in Hong Kong, menjelaskan bahwa elemen penting terhadap keluarga dalam meningkatkan status kesehatan anggota keluarga yang mengalami halusinasi pendengaran di Hongkong menyatakan bahwa pasien dengan skizofrenia sangat membutuhkan perawatan oleh keluarga dengan baik untuk membantu proses penyembuhan pasien. Pentingnya peranan keluarga dalam proses penyembuhan klien halusinasi pendengaran akan mempengaruhi proses penyembuhan klien.

\section{METODE PENELITIAN}

Penelitian ini menggunakan rancangan penelitian kualitatif dengan pendekatan fenomologi bertujuan untuk mengeksplorasi pengalaman keluarga dalam merawat anggota keluarga yang menderita halusisnasi pendengaran. Polit dan Beck (2008), mengidentifikasikan fenomena deskriptif dalam empat langkah antara lain: bracketing, intuiting, analyzing, dan describing. Pengambilan partisipan dengan cara purposive sampling dengan Jumlah partisipan sebanyak 7 orang dengan kriteria keluarga inti yang mempunyai pengalaman merawat anggotanya yang menderita halusinasi, Keluarga inti yang tinggal bersama anggota keluarga dengan halusinasi dan memiliki pengalaman dalam data dengan menggunakan Credibility analisa data metode Colaizzi. Uji data dengan menggunakan Credibility dengan membercheck, Transferability, Dependability, Comfirmability.

\section{HASIL DAN PEMBAHASAN}

Hasil dari penelitian dapatkan empat tema antara lain: 1) Jenis Perawatan halusinasi pendengaran yang keluarga di rumah 2) Temuan keluarga dalam merawat, 3) Jenis penyelesaian masalah daam keluarga 4) Pelayanan yang di dapatkan

\section{Tema 1. Jenis Perawatan halusinasi pendengaran yang keluarga di rumah}


Tiga pernyataan dari partisipan:

“........makannya saya sendiri yang ngasih, ngurusin pakaiannya, mandi harus selalu diingatin, waduh buk saya benar-benar berusaha untuk dia......"(P4)

“.........sekarang ini kontrol terus setiap bulan, saya ini lah buk yang ngambilin obat terus karena keluarga lain tidak ada bu, bapak saya kerja......."(P2)

“............sekarang ini kan dia sudah tenang buk, jadi saya suruh dia belanja ke warung, beli miwon jadilah atau beli garam, yang penting dia ada interaksi dengan orang lain, biar tidak kaku di rumah.......(P6)

\section{Tema 2: Temuan keluarga dalam merawat}

"............saya itu buk masalah uang untuk berobat, untuk ongkos angkotlah buk saya sediakan dari uang makan kami, ya kadang-kadang makan tidak cukup, seadanya, yang penting bagi saya obatnya ada....."(P4)

".......saya rasa orang Jambi ni susah nerima orang sakit jiwa ini bu, ada yang ngejek, ada juga la yang tidak, kan tidak semua buk...."(P7

“......kadang kami pulang kerja tu kesal juga mbak melihat anak itu banyak perangai dan setelah aku marah baru aku sadar ya Allah beri aku kesabaran...."(P1)

\section{Tema 3: Jenis penyelesaian masalah daam keluarga}

"...... di bawa kerumah sakit, kalau-kalau ada gangquan jiwa katanya, makanya kami bawa berobat kesini bu, dirawat dulu enam bulan, sudah sehat dari sini dirawat dirumah lagi, sekarang ini kontrol terus setiap bulan....."(P1)

“......usaha lain juga buk di bawa ke pengobatan alternatif yang di Mayang, dibekam la disitu, aduh sudah macam-macam la buk sejak enam taun ni usaha kami untuk $A$ ni biar sehat....."(P5)

\section{Tema 4: Pelayanan yang di dapatkan}

Pelayanan yang di dapatkan keluarga dalam merawat halusinasi pendengaran dapat dilihat dalam ungkapan dari dua partisipan dibawah ini:

“.... Rumah Sakit ini membuat kami merasa terbantu......"(P3)

“......kadang puskesmas juga bisa ambil obat, tapi paling enak tu di Rumah Sakit......"(P5)

\section{Pembahasan}

Tema 1: Jenis Perawatan halusinasi pendengaran yang keluarga di rumah

Perawatan pada pasien halusinasi pendengaran dilakukan oleh keluarga inti seperti suami/istri, kakak kandung/ adik kandung. Shives (2012), menjelaskan bahwa keluarga merupakan sekelompok individu yang saling berinteraksi, memberikan dukungan dan saling mempengaruhi satu sama lain. Menurut hasil dari penelitian membuktikan bahwa bantuan keluarga dapat mempercepat proses pengobatan pasien halusinasi pendengaran . Julianti (2013), dalam penelitiannya menyatakan bahwa yang melakukan perawatan pada anggota keluarga yang sakit adalah anggota keluarga itu sendiri sehingga yang berperan sebagai caregiver adalah anggota keluarga inti. Menurut Butar (2012), keluarga harus berperan aktif dalam pengawasan minum obat pasien supaya pasien patuh dalam mengkonsumsi obat terutama pada penyakit menahun seperti skizofrenia. keluarga membantu pasien dalam bersosialisasi dengan lingkungan. Menurut Agung (2010), dalam penelitiannya mengatakan frekuensi kekambuhan pasien sangat tergantung pada keluarga dalam mengaplikasikan program rawat jalan

Adanya hasil penelitian ini diharapkan kepada perawat jiwa agar memaksimalkan program edukasi pada keluarga pasien terkait dengan membantu bersosialisasi dengan lingkungan karena jika pasien selalu berada di dalam rumah, maka akan sulit bagi pasien dan keluarga dalam melakukan proses penyembuhan dikhawatirkan pasien akan semakin menarik diri dan sulit untuk berinteraksi dengan orang lain.

\section{Tema 2: Temuan keluarga dalam merawat}

Keluarga mengemukakan temuan dalam merawat anggotanya yang menderita halusinasi seperti yang diungkapkan oleh partisipan dalam penelitian ini yaitu terkait dengan masalah dalam keuangan, stigma masyarakat pada keluarga gangguan jiwa, masalah emosional dalam merawat. Berdasarkan penelitian Muesser \& Gingerich (2006), dengan judul the Complete Family Guide to Skizofrenia in New York, menjelaskan dalam penelitiannya mengatakan bahwa anggota keluarga dengan skizofrenia akan menjadi masalah finansial bagi keluarga yang lain sehingga anggota keluarga tersebut akan menjadi terbebani dalam kehidupan sehari-hari. Di dukung oleh hasil penelitian Guraj, G.P, Boda, M.S, Reddy (2008), dengan judul Family Burden, Quality of Life and Disabilityin Obsesive Conpulsive Disorder in Indian, enam dimensi beban keluarga dengan skizofrenia, dimana faktor finansial menempati masalah yang paling berat yang dirasakan oleh keluarga dalam melakukan perawatan. Menurut Maglaya (2009), masalah yang diterima keluarga terkait dengan stigma dari keluarga atau masyarakat dimana keluarga harus memiliki kemampuan tentang cara merawat klien. Seperti yang diungkapkan oleh patisipan tiga (P3) dalam penelitian ini bahwa terkadang masyarakat bahkan keluarga sendiri yang menyalahkan pihak keluarga yang merawat tanpa memikirkan usaha yang telah dilakukan keluarga dan tanpa menimbang perasaan anggota keluarga itu sendiri. Selain itu masalah psikologis yang dirasakan anggota keluarga seperti perasaan kehilangan, sedih, malu, stres menghadapi gangguan perilaku dan frustasi akibat perubahan pola komunikasi dalam keluarga WHO (2010) 


\section{Tema 3: Jenis penyelesaian masalah daam keluarga}

Bermacam permasalahan yang dirasakan partisipan selama merawat anggota keluarga dengan halusinasi pendengaran, namun setiap permasalahan yang dialami selalu mempunyai jalan keluar dalam menyelesaikannya.

Bantuan medis yang dilakukan oleh keluarga terkait dengan bantuan tenaga kesehatan dan bantuan pelayanan kesehatan. Selain mencari bantuan medis, keluarga juga telah berusaha dalam mencari pertolongan non medis, hal ini dilakukan keluarga karena awalnya tidak mengetahui dan tidak meyakini bahwa pasien menderita gangguan kejiwaan.

Menurut Keliat (2011), Tindakan keperawatan halusinasi pada anggota keluarga dirumah yaitu keluarga mengenal masalah merawat pasien halusinasi dirumah seperti keluarga merawat pasien dengan halusinasi, keluarga menciptakan lingkungan yang nyaman untuk klien dengan halusinasi, keluarga mengenal tanda dan gejala kambuh ulang, keluarga mampu memanfaatkan fasilitas kesehatan.

Menurut Napoleon (2010), upaya keluarga dalam menangani anggota keluarga yang sakit dengan cara mencari bantuan dari pihak tenaga alternatif seperti paranormal, tabib dan orang-orang pintar yang dianggap mampu menyelesaikan permasalahan yang dirasakan anggota keluarga.

Hasil penelitian ini dapat disimpulkan upapun upaya yang telah dilakukan keluarga seperti mencari bantuan tenaga kesehatan maupun bantuan tenaga alternatif lainnya didasarkan oleh pengalaman keluarga dan pengalaman masyarakat yang ada sebelumnya dan disertai dengan keyakinan akan mendapatkan pertolongan.

\section{Tema 4: Pelayanan yang di dapatkan}

Menurut ungkapan dari empat partisipan, pelayanan kesehatan seperti peningkatan pelayanan kesehatan yang lebih baik dari yang sekarang dalam hal ini perawat agar selalu melayani dengan senyuman, dan pihak pemberi pelayanan kesehatan bersedia untuk memberikan motivasi baik pada pasien maupun keluarga dengan melakukan kunjungan rumah, selain itu keluarga juga mengharapkan agar selalu mendapatkan bantuan pengobatan dari pemerintah dalam biaya pengobatan.

Selain itu kunjungan kerumah keluarga yang di lakukan oleh perawat akan sangat membantu proses penyembuhan klien, namun keterbatasan dari tenaga kesehatan yang membuat kunjungan rumah ini belum berjalan sebagaimana semestinya. Keterbatasan dari tenaga kesehatan dan dana juga dapat diatasi dengan pembentukan kader kesehatan jiwa di masyarakat, yang dibentuk melalui peran serta perawat jiwa komunitas (Community Mental Helath Nursing) (Keliat, 2010: Depkes, 2010)

Beberapa asumsi peneliti rangkum dalam hal ini bahwa harapan yang benar-benar diharapkan oleh pihak keluarga pada pemberi pelayanan kesehatan adalah adanya jadwal kunjungan rumah satu bulan sekali untuk mengontrol proses perawatan dan pengobatan. Tentunya harapan pada pemerintah adanya bantuan biaya pengobatan dan perawatan pada keluarga yang menderita halusinasi.

\section{SIMPULAN}

Pentingnya deteksi dini malalah kambuh pada gangguan jiwa untuk menekan angka kekambuhan melalui peran tenaga kesehatan, kader , dan melibatkan keluarga.

\section{Saran}

Bagi tenaga kesehatan tentunya sangat diperlukan kunjungan rumah bagi keluarga yang anggota keluarganya menderita gangguan jiwa minimal 1 bulan sekali.

\section{DAFTAR PUSTAKA}

Agung, P (2010). Faktor- Faktor Yang Berhubungan Dengan Kekambuhan Pasien Skizofrenia di Rumah Sakit Jiwa Daerah Surakarta. Jurnal Keperawatan Vol. 1 No.1

Butar, B.O.D (2012) Hubungan Pengetahuan Keluarga dengan Tingkat Kepatuhan Pasien Skizofrenia di Sumatera Utara. Di unduh melalui http://respiratory.usu.ac.id. Di akses pada tanggal 15 September 2015

Froggatt, W (2005). A Brief Introduction To Rational Emotive Behaviour Therapy, Journal Of Rational Emotive Behaviour Therapy. Diakses pada tanggal 29 Juli 2015

Friedman. (2010). Buku Ajar Keperawatan Keluarga Riset, Teori dan Praktek. Edisi 5. EGC.Jakarta

Greenberg, Kim, Greenley (1997). Family Responses from Westernized Cuontries: The Online JournalOf Issue in Nursing. Diunduh melalui http://www.nursingworld.org/.

Issaacs, A. (2005). Keperawatan Kesehatan Jiwa dan Psikiatri. Edisi 3. Jakarta: EGC

Julianti (2013). Pengalaman Caregiver Dalam Merawat Pasien di Rumah di Tanggerang Selatan.

Kaplan \& Saddock (2010). Buku Ajar Psikiatrik Klinis. Jakarta. EGC

Kelliat, B.A. (2011). Proses Keperawatan Jiwa Dalam Konteks Keluarga. Jakarta: EGC

Kozier, Erb (2010). Buku Ajar Praktik Keperawatan Klinis. Jakarta: EGC

Napolion, K (2010). Studi Fenomenologi: Pengalaman Keluarga Merawat Anak Dengan Tunagrahita di Kecamatan Bogor Barat. Tesis, FIK UI. Diakses pada tanggal 2 Agustus 2015.

Polit, D. F \& Beck, C. T (2008). Nursing Research Principles And Methods. Philadelphia: Lipincott Williams and Wilkins

Potter, P. A \& Perry, A.G. (2005). Fundamentals of Nursing: Conceps, Proses, and Pracice. (4 th Ed). Philadelphia: Mosby-Years Book-inc

Shives, R.L. (2012). Basic Consepts of Psychiatric Mental Health Nursing. (8 th Ed). Wolters Kluwer. Longwood. Forida

Stuart, G.W \& Laraia, M. T (2009). Principles and Practice of Psychiatric Nursing. (8 th Ed). St. Louis: Mosby

Towsend, C.M. (2011). Essentials Of Psychiatric Mental Health Nursing. (5 th Ed). Philadelphia: F.A. Davis Company

Vanders, S.\& Vandevelde (2012). Recovering From Hallusinations: A Qualitative Study of Coping with Voices Hearing of People with Schizofrenia in 
Hongkong. The Scientific Wold Journal. Vol. 2012.

ID 232619, 8 Pages

World Health Organization (2010). Schizofrenia.

Diunduh melalui

http://www.who.int/mental health/management/sc

hizofrenia/en/. 